\title{
Reevaluation of some properties of fibrinogen, purified from cord blood of normal newborns
}

Citation for published version (APA):

Hamulyak, K., Nieuwenhuizen, W., Devilee, P. P., \& Hemker, H. C. (1983). Reevaluation of some properties of fibrinogen, purified from cord blood of normal newborns. Thrombosis Research, 32(3), 301310. https://doi.org/10.1016/0049-3848(83)90165-2

Document status and date:

Published: 01/11/1983

DOI:

10.1016/0049-3848(83)90165-2

Document Version:

Publisher's PDF, also known as Version of record

\section{Please check the document version of this publication:}

- A submitted manuscript is the version of the article upon submission and before peer-review. There can be important differences between the submitted version and the official published version of record.

People interested in the research are advised to contact the author for the final version of the publication, or visit the DOI to the publisher's website.

- The final author version and the galley proof are versions of the publication after peer review.

- The final published version features the final layout of the paper including the volume, issue and page numbers.

Link to publication

\footnotetext{
General rights rights.

- You may freely distribute the URL identifying the publication in the public portal. please follow below link for the End User Agreement:

www.umlib.nl/taverne-license

Take down policy

If you believe that this document breaches copyright please contact us at:

repository@maastrichtuniversity.nl

providing details and we will investigate your claim.
}

Copyright and moral rights for the publications made accessible in the public portal are retained by the authors and/or other copyright owners and it is a condition of accessing publications that users recognise and abide by the legal requirements associated with these

- Users may download and print one copy of any publication from the public portal for the purpose of private study or research.

- You may not further distribute the material or use it for any profit-making activity or commercial gain

If the publication is distributed under the terms of Article $25 \mathrm{fa}$ of the Dutch Copyright Act, indicated by the "Taverne" license above, 
K. Hamulyăk ${ }^{1}$, W. Nieuwenhuizen ${ }^{2}$, P.P. Devilée ${ }^{1}$ and H.C. Hemker ${ }^{1}$

\section{Department of Biochemistry, Biomedical Centre,} University of Limburg,

postal address: P.0. Box 616,6200 MD Maastricht, the Netherlands. and Gaubius Institute, Health Research Division TNO,

Herenstraat 5d, 2313 AD Leiden, the Netherlands.

(Received 30.3.1983; Accepted in revised form 15.7.1983 by Editor V.V. Kakkar)

(Received in final form by Executive Editorial office 26.8.1983)

\section{ABSTRACT}

In this study we compared some properties of fibrinogens, obtained from normal adult and cord plasma. Fibrinogen preparations were made under conditions, which minimize proteolytic breakdown in vitro. We were not able to demonstrate any significant differences between both purified fibrinogens as to the effects of $\mathrm{pH}$ and ionic strength on its clotting properties, the $k$ for thrombin, SDS polyacrylamide gelelectrophoresis behaviour or carbohydrate content.

However, the phosphorus content of cord fibrinogen was 3-4 times higher than that of adult fibrinogen.

The accelerating effect of calcium on the thrombin clotting time was more pronounced for newborn cord plasma and for purified cord fibrinogen preparations as compared with adult fibrinogen. This might be explained by the higher phosphorus content of the cord fibrinogen molecule.

The thrombin clotting time of both purified adult and cord fibrinogen was markedly prolonged, when increasing amounts of fibrinogen degradation product fragment $X$ were added to the fibrinogen solutions under conditions with high $\mathrm{pH}$ or high ionic strength. At high $\mathrm{pH}$ the effect of adding fragment $\mathrm{X}$ was more pronounced in cord fibrinogen preparations. Therefore, mixtures of purified fibrinogen and fragment $x$ have several properties in common with fetal fibrinogen.

These observations show, that some of the properties that have been attributed in the literature to a distinct fetal fibrinogen can be caused by the presence of fragment $X$ in the cord fibrinogen preparations.

Key words: cord fibrinogen, purification, properties 


\section{INTRODUCTION}

The possible existence of a distinct fetal fibrinogen was first reported by Burstein and coworkers in 1954 (1). They compared some optical and mechanical properties of clots of newborn and adult fibrin and found that a clot of fibrin of newborns was more transparant and less compressible than a clot of fibrin of adults. The difference was relatively pronounced at $\mathrm{pH}$ 8.6 but hardly detectable at $\mathrm{pH}$ 6.9. Künzer (2) noted that whereas the level of most clotting factors was low, the level of fibrinogen in the newborn was usually the same as in the adult, however Künzer also noted differences in properties.

He postulated a functionally different fibrinogen in the newborn with an accelerated fibrinogen-fibrin transition.

Witt (3-9) isolated fibrinogen from human umbillical cord blood.

She found a significantly retarded thrombin-catalysed conversion of cord fibrinogen to fibrin at $\mathrm{pH}^{\prime} \mathrm{s}$ around 7. The difference was even more pronounced at pH 8.5. Electron microscopic comparison of fetal fibrin clots with those from adults showed shorter and thinner fibers, which might be a corrolary of the old observation that the fibrin clots in newborn plasma are more transparant $(8,9)$.

Galanakis (10-12) emphasized the importance of the solvent conditions, especially of the ionic strength in the testing systems. He found that relatively high ionic strengths prolong the thrombin clotting time of cord fibrinogen more than that of adult fibrinogen. In agreement with Guillin (13) he found a slower rate and a lower degree of aggregation of fetal fibrin monomers as compared with adult fibrin monomers at high ionic strength.

Teger-Nilsson (14) found only a slightly lower aggregation rate of fetal fibrin monomers and no significant prolongation of the thrombin clotting time at a physiological ionic strength and $\mathrm{pH}$. This was also reported by Krause (15). Teger-Nilsson found no differences between the two types of fibrinogen on polyacrylamide gel electrophoresis and mapping of tryptic peptides of reduced and alkylated polypeptide chains.

Witt and coworkers (3-9) described extensively the molecular properties of purified cord fibrinogen. The overall amino acid composition of newborn fibrinogen was virtually the same as that of adult fibrinogen. On the basis of data obtained by fingerprinting tryptic digests, she postulated that at least three peptides differ in newborn as compared with adult fibrinogen. Fetal fibrinogen has been reported to contain the same amount of hexose, but almost twice the amount of phosphorus of adult fibrinogen (5). This probably did not explain the functional differences because enzymatic dephosphorylation did not correct the functional properties of fetal fibrinogen. On DEAE cellulose column chromatography the major fibrinogen peak from newborn fibrinogen preparations eluted somewhat later than those obtained from adult material. The apparent $K_{m}$ for thrombin was lower for fetal than for adult fibrinogen, suggesting a greater affinity of thrombin for fetal than for adult fibrinogen.

In 1979 Galanakis reported that partial removal of sialic acid shortened the prolonged thrombin clotting time of fetal fibrinogen. He found the sialic acid content of fetal fibrinogen to be higher than that of adult fibrinogen (12). This was also reported by Lane, who described a markedly different carbohydrate composition of fetal fibrinogen, particularly an increased sialic acid content (16).

Galanakis reported in 1977 that a mixture of adult and fetal fibrinogen is found in the cord plasma of full-term infants. In premature infants there 
is relatively more fetal fibrinogen (11).

Mills and Karpatkin (17) challenged the existence of a distinct fetal fibrinogen. They concluded that the delay of clotting of cord fibrinogen is due to a greater content of preformed fibrin in these preparations and could not relate the heterogeneity of adult fibrinogen to the persistance of a fetal fibrinogen.

Also other authors questioned the existence of a distinct fetal fibrinogen $(18,19,20)$.

Loly (21) could not find any difference between adult and fetal sheepfibrinogen.

Alltogether there is still a lot of controversy about the properties of the so called fetal fibrinogen and even its existence is doubted. Indeed the variations in experimental results can be explained by differences in purification methods and solvent conditions in the testing systems. Also artefacts, introduced by 1 imited proteolysis in vitro cannot be precluded. We therefore reexamined the problem under conditions, where special care was taken to prevent proteolysis in vitro.

We also measured the influence of adding increasing amounts of fragment $X$ to see whether the reported differences between preparations of newborn and adult fibrinogen could be explained by the presence of degradation products in the former.

\section{MATERIALS AND METHODS}

Blood samples were obtained from the umbillical cords of normal full-term infants by venapuncture, immediately after clamping the umbillical cord. The Apgar score of the infants was more than 7 after one minute, the pH of the umbillical vein blood greater than 7.20 and the birth weights were all in the normal range. There were no signs of fetal distress before parturition and no macroscopic alterations of the placenta and the umbillical cord were observed.

The mothers did not receive any medication, reported to possibly influence the haemostatic reaction in the child.

The first few $\mathrm{ml}^{\prime} \mathrm{s}$ of cord blood after a clean venapuncture were discarded. The blood was then collected in an anticoagulant medium containing $1 \%(\mathrm{w} / \mathrm{w})$ $\mathrm{Na}{ }_{2}$ EDTA, $0.9 \%(\mathrm{w} / \mathrm{w}) \mathrm{NaCl}$ and $400 \mathrm{~K}$.I.U. Trasylol per ml. 9 volumes of blood were mixed with 1 volume of anticoagulant medium.

Immediately after blood sampling $1 \%(\mathrm{v} / \mathrm{v})$ di-isopropylphosphofluoridate (DFP) solution ( $0.1 \mathrm{M}$ in dry isopropanol) was added to prevent proteolysis vitro. The samples were centrifuged for 15 minutes at $1500 \mathrm{~g}$ in a swing-out rotor. The plasma was centrifuged at $20.000 \mathrm{~g}$ for twenty minutes to remove blood platelets and other particulate elements.

The plasma was then diluted to 1.5 times the original blood volume with a phosphate buffer, $0.15 \mathrm{M}, \mathrm{pH} 7.5$, containing per liter $22.3 \mathrm{gr} . \mathrm{K}_{2} \mathrm{HPO}_{4}, 3$ gr. $\mathrm{KH}_{2} \mathrm{PO}_{4}, 1.1 \mathrm{gr}$. $\mathrm{Na}{ }_{2} \mathrm{EDTA}, 0.1 \mathrm{gr} \cdot \mathrm{NaN}_{3}$ and $20.000 \mathrm{~K}$.I.U. Trasylo1.'At each step ${ }^{\prime} \%(\mathrm{v} / \mathrm{v})$ DFP solution was added?

Cord plasma's of five newborns were combined to give a pool of approximately $100 \mathrm{~m} 1$ plasma and stored at $-20^{\circ} \mathrm{C}$ untill further use. The cord blood was obtained with the kind coöperation of the staff of the Midwivery School in Heerlen (Head: Dr. R. Oomers).

Adult blood was collected and plasma prepared from healthy donors as described above.

Purification of Fibrinogen:

Fetal and adult fibrinogen were purified from $100 \mathrm{ml}$ cord plasma and adult plasma respectively, by the procedure to be described below. The plasma was applied to a Sepharose-1ysine column $(2.8 \times 13 \mathrm{~cm})$ to remove plasminogen. The 
eluate was brought to $25 \%$ saturation in $\left(\mathrm{NH}_{4}\right)_{2} \mathrm{SO}_{4}(13.9 \mathrm{gr} / 100 \mathrm{ml})$, stirred for one hour at $4{ }^{\circ} \mathrm{C}$ and centrifuged for twenty minutes at $3000 \mathrm{~g}$. The precipitate was dissolved in phosphate buffer to 1.5 times the original blood volume and again precipitated at $25 \%\left(\mathrm{NH}_{4}\right)_{2} \mathrm{SO}_{4}$ saturation. This precipitate was dissolved in a minimum volume of phosphate buffer and gel filtered on a Sepharose $6 \mathrm{~B}$ column $(2 \times 120 \mathrm{~cm})$ at $4{ }^{\circ} \mathrm{C}$. The second peak (absorbance at $280 \mathrm{~nm}$ ) contains virtually pure fibrinogen. The purification procedure has been described in detail elsewhere (Van Ruyven-Vermeer et a1. 22).

SDS polyacrylamide gelelectrophoresis was performed according to standard procedure with and without $\beta$-mercaptoethanol (23).

Thrombin clotting time: Fibrinogen concentrations were adjusted to $1 \mathrm{mg} / \mathrm{ml}$. Aliquots of $0.200 \mathrm{ml}$ fibrinogen solutions were preincubated for 30 seconds at $37{ }^{\circ} \mathrm{C}$. The reaction was started with $0.050 \mathrm{ml}$ of a bovine thrombin solution ( $\left.5 \mathrm{~N} . \mathrm{I}_{\mathrm{H}} \mathrm{H} / \mathrm{m} \mathrm{l}\right)$ (Roche, Basel) and the clotting time recorded with the use of a Kolle Hook.

The influence of the pH of the fibrinogen solutions on the thrombin clotting time was studied by varying the $\mathrm{pH}$ by dialysing before the experiment against buffers containing $0.15 \mathrm{M} \mathrm{NaCl}$ and $0.01 \mathrm{M}$ Tris. Ionic strengths were varied in the range of 0.05 to $0.30 \mathrm{M} \mathrm{NaCl}$ at a constant $\mathrm{pH}$ 7.4. The influence of calcium added to the thrombin solution was also studied. To estimate the $\mathrm{K}$, the clotting times were obtained with fibrinogen solutions of different concentrations.

Fragment $X$ was prepared by limited plasmin digestion of purified adult fibrinogen and purified according to W. Nieuwenhuizen and Gravesen (24).

The effect of adding increasing amounts of fragment $X$ on the thrombin clotting time of cord and adult fibrinogen was studied, especially under conditions with a high $\mathrm{pH}$ and high ionic strength.

Carbohydrate determination: the carbohydrate analyses were performed essentially as described by Kamerling and Clamp (25). They were carried out by Drs. J.P. Kamerling, G.J. Gerling and J.F.G. Vliegenthart, Laboratory of Organic Chemistry, University of Utrecht, Utrecht, The Netherlands. Before analysis samples of fibrinogen were run through a Bioge1-P 60 column in $0.15 \mathrm{M} \mathrm{NaCl}$, dialysed extensively against several changes of distilled water and freeze-dried.

Phosphorus determination: phosphorus determinations were carried out according to Böttcher (26). Before analysis samples of fetal and adult fibrinogen were dialysed against several changes of twice-distilled water and freeze-dried. To check the possibility that the phosphorus in the fibrinogen originates from bound phospholipids, the fibrinogenpreparations were extracted according to the following procedure: $20 \mathrm{mg}$ portions of fetal and adult fibrinogen in $10 \mathrm{ml} 0.15 \mathrm{M}$ NaCl were dialyzed against distilled water and freeze-dried.

$10 \mathrm{ml} \mathrm{NaCl}(0.15 \mathrm{M})$ was also dialyzed and freeze-dried, to serve as a control. To the residues $40 \mathrm{ml}$ methanol: chloroform $=1: 2$ was added and the mixture heated for 15 minutes at $60^{\circ} \mathrm{C}$. After cooling to room temperature 9 $\mathrm{m} 10.15 \mathrm{M} \mathrm{NaCl}$ was added to each tube and shaken well.

After centrifugation to separate the phases, the upper layers were removed, the bottom layers were washed once with methanol: chloroform: water = 48:4:47 and centrifuged again. The remaining bottom layers were evaporated under a stream of nitrogen, taken up in $0.5 \mathrm{ml}$ chloroform and the amount of phospholipids determined according to van Gent (27). 


\section{RESULTS AND DISCUSSION}

In contrast with some reports in the literature we found no significant different influences of the $\mathrm{pH}$ and/or the ionic strength on the thrombin clotting time of adult and cord fibrinogen.

Only at high ionic strength $(0.30 \mathrm{M} \mathrm{NaC1})$ and high $\mathrm{pH}(9.0)$, the thrombin clotting time seems to be slightly prolonged with cord as compared with adult fibrinogen. However, it is difficult to decide how significant these differences are, since it was difficult to assess the clotting times accurately under these conditions.

The pH optimum for the thrombin-catalysed transition of both adult and cord fibrinogen to fibrin was 7.4 .

The $\mathrm{K}_{\mathrm{m}}$ values for the interaction of thrombin (bovine) with adult and cord fibrinogen were determined by measuring clotting times with varying fibrinogen concentrations at a fixed thrombin concentration. The results are shown in figure 3. In this figure use has been made of the fact, that the clotting time is proportional to $1 / v(v)$ velocity of the overall fibrinogen conversion reaction in an experimental set up)(28). As can be concluded from this figure, no significant differences could be found between the $\mathrm{K}_{\mathrm{m}}$ 's of adult and cord fibrinogen. The values found were 0.70 and $0.62 \mu \mathrm{M}$ respectively.

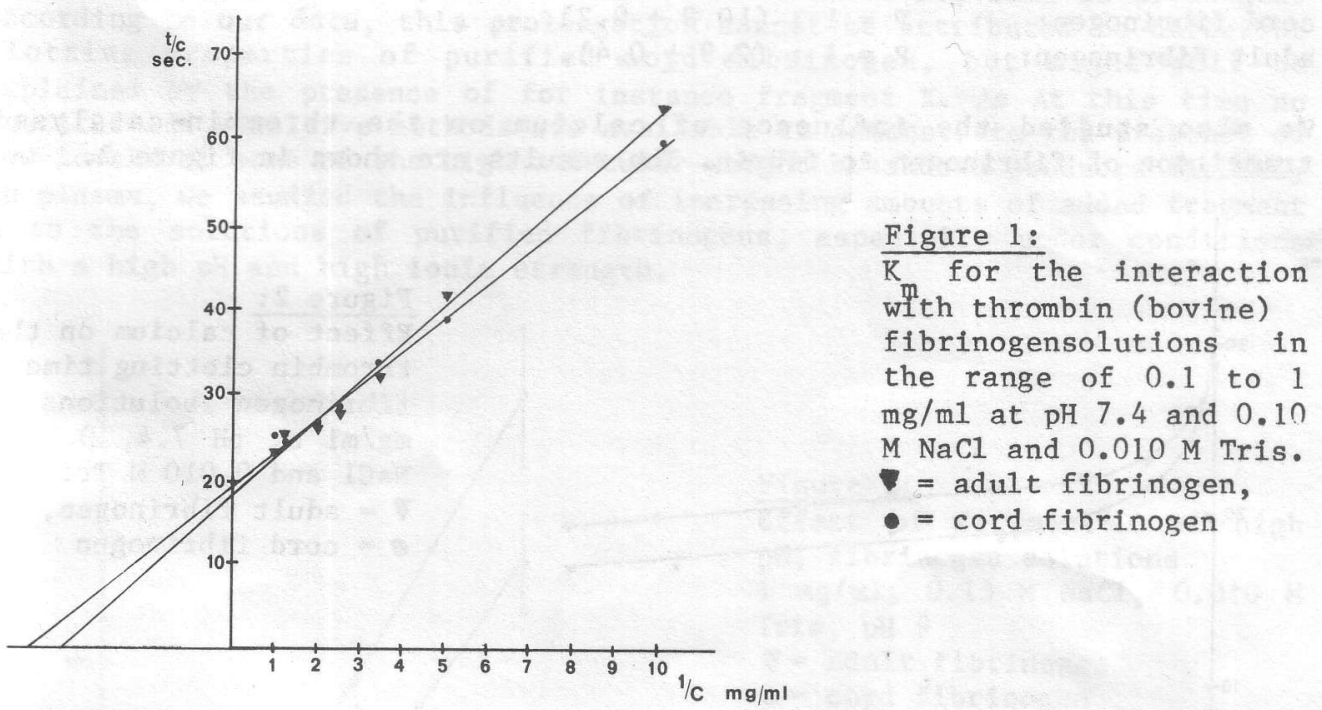

Electrophoresis on SDS polyacrylamide gels containing $\beta$-mercapto-ethanol showed no difference between adult and cord fibrinogen (not shown). The carbohydrate compositions of cord fibrinogen and adult fibrinogen are essentailiy the same (table 1 ) and the results are in accordance with the data of Townsend (29) for adult fibrinogen.

Differences in the sialic acid content, reported in the literature $(12,16)$ were not confirmed. 
TABLE 1

A. Carbohydrate Composition of Adult and Cord Fibrinogen

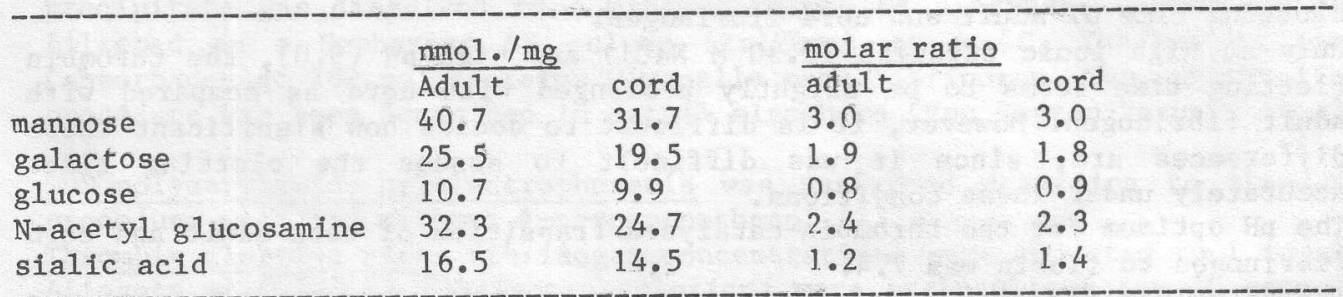

We could confirm that the phosphorus content is 3 to 4 times higher in cord fibrinogen than in adult fibrinogen (5). It could be excluded that his was due to contamination with phospholipids, because after lipid extraction virtually no phosphorus was found in the extracts. The results are shown in table 2.

TABLE 2

Phosphorus Content of Adult and Cord Fibrinogen (molar ratio)

cord fibrinogen: $\quad P=1:(10.9 \pm 0.2)$.

adult fibrinogen: $\quad P=1:(2.9 \pm 0.4)$.

We also studied the influence of calcium on the thrombin-catalysed transition of fibrinogen to fibrin. The results are shown in figure 2.

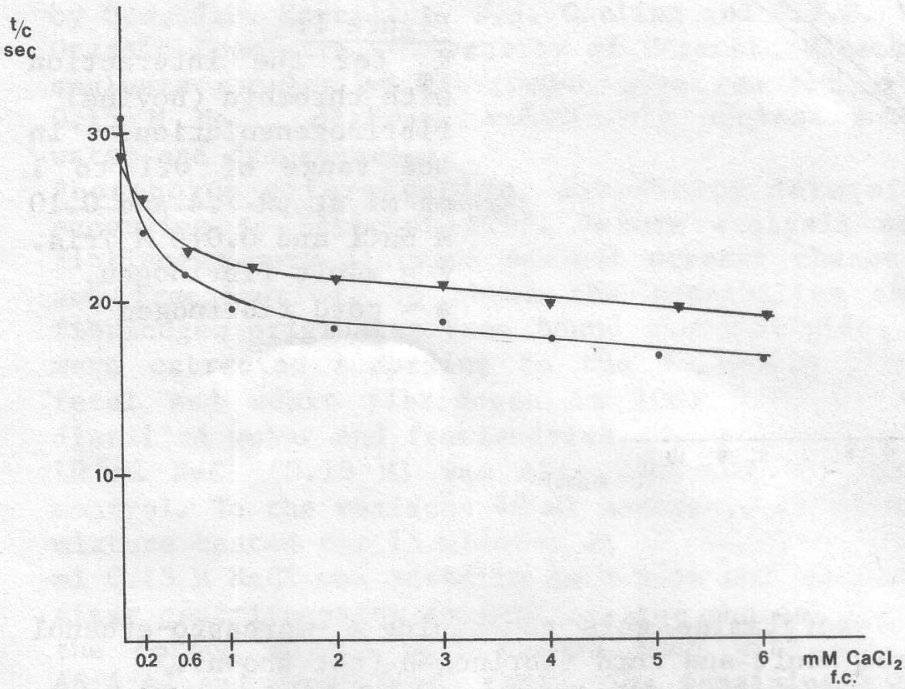

From this it can be seen that the procoagulant effect of adding calcium to the thrombin solution is more pronounced in the preparations of cordfibrinogen than in those of adult fibrinogen.

Some of the properties, ascribed to a distinct fetal fibrinogen species, might be explained by the occurence of contaminants, especially fibrinogen

\begin{abstract}
Figure 2:
Effect of calcium on the thrombin clotting time fibrinogen solutions 1 $\mathrm{mg} / \mathrm{m} 1$ at $\mathrm{pH} 7.4,0.15 \mathrm{M}$ $\mathrm{NaCl}$ and $0.010 \mathrm{M}$ Tris - = adult fibrinogen, - cord fibrinogen
\end{abstract}


breakdown products, in some cord fibrinogen preparations. These might have been formed in vivo or in vitro. We tried to minimize fibrinogen proteolysis in vitro in our purification procedure.

No fibrinogen degradation products were observed in our purified cord and adult fibrinogen preparations. This indicates that such degradation products do not occur in vivo in detectable amounts or that they have been lost during the purification of the fibrinogen. The latter possibility would lead to a correction of the apparent abnormalities observed with cord plasma as a result of the purification.

The occurence of degradation products in newborn blood in vivo is likely, since it is known that in the sick newborn a marked degree of diffuse intravascular coagulation is quite common, probably related to hypotension, hypothermia, hypoxia, acidosis, poor tissue perfusion, hepatic immaturity and a poorly developped reticulo endothelial system, which may prevent adequate clearing of activated coagulation factors and therefore enhance the sequala of diffuse intravascular coagulation.

The enhanced fibrinolytic capacity of cord blood of normal newborns is well documented in the literature (30) and may be the cause of some proteolysis of fibrinogen.

If demonstrated, the presence of degradation products in cord plasma could explain some of the properties, ascribed to fetal fibrinogen. It is known, that fragment $X$, for instance is a potent inhibitor of the action of thrombin on fibrinogen and polymerization of fibrin monomers (24). In nearly all newborn cord plasma's the thrombin clottting time is prolonged. According to our data, this prolongation cannot be attributed to different clotting properties of purified cord fibrinogen, but might well be explained by the presence of for instance fragment $X$. As At this time no specific and sensitive methods are available to demonstrate the presence of low levels of some of the high molecular weight breakdown products directly in plasma, we studied the influence of increasing amounts of added fragment $X$ to the solutions of purified fibrinogens, especially under conditions with a high $\mathrm{pH}$. and high ionic strength.

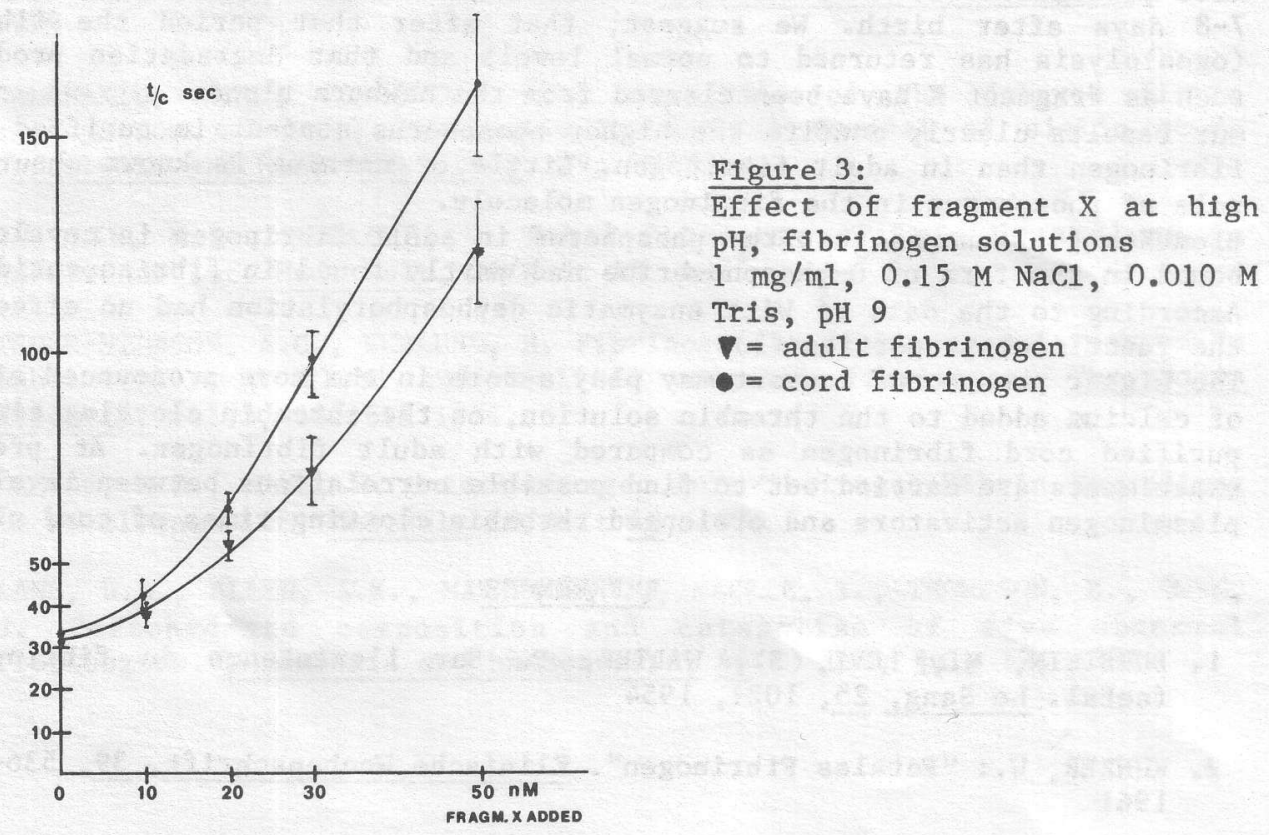


As can be seen in figure 3, the thrombin clotting time of cord fibrinogen appeared to react stronger to the addition of fragment $X$ than adult fibrinogen at $\mathrm{pH}$ 9. No differences were recorded between the two types of fibrinogen at high ionic strength, when increasing amounts of fragment $X$ were added to the fibrinogen solutions.

This is shown in figure 4 .

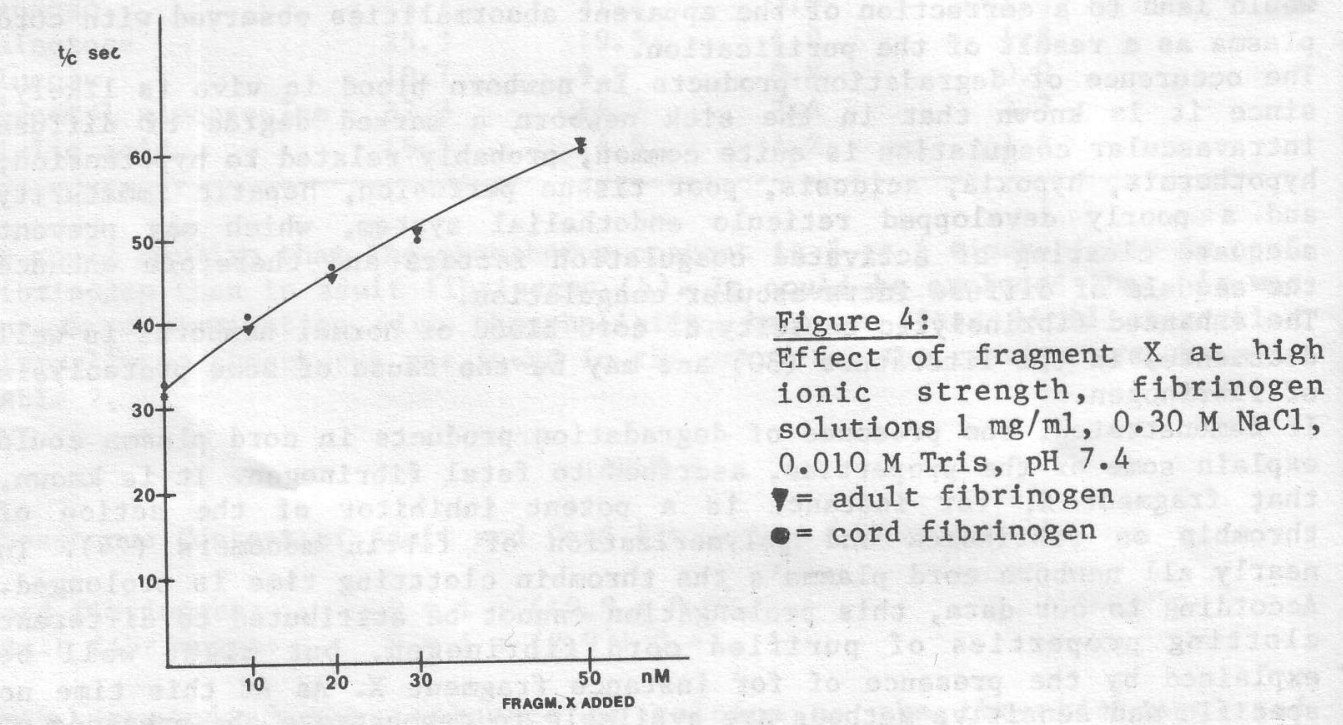

These results suggest that some of the clotting properties, ascribed in the literature to fetal fibrinogen may be due to a contamination with degradation products such as fragment $\mathrm{X}$.

Witt postulated (9) that the synthesis of fetal fibrinogen lasts only for 7-8 days after birth. We suggest, that after that period the fibrin(ogen)olysis has returned to normal levels and that degradation products such as fragment $X$ have been cleared from the newborn blood.

Our results clearly confirm the higher phosphorus content in purified cord fibrinogen than in adult fibrinogen. Little or nothing is known about the role of phosphorus in the fibrinogen molecule.

Blombäck (31) showed that the phosphorus in adult fibrinogen is covalently bound in the form of 0 -phosphoserine and partly found in fibrinopeptide A. According to the data of Witt enzymatic dephosphorylation had no effect on the functional properties (5).

The higher phosphorus content may play a role in the more pronounced effect of calcium added to the thrombin solution, on the thrombin clotting time in purified cord fibrinogen as compared with adult fibrinogen. At present experiments are carried out to find possible correlations between levels of plasminogen activators and prolonged thrombin clotting times of cord plasma

\section{RFFFRENCES}

1. BURSTEIN, M., LEVI, S., WALTER, P. Sur l'existence du fibrinogène foeta1. Le Sang, 25, 1021, 1954

2. KUNZER, W.: "Fetales Fibrinogen". K1inische Wochenschrift, 39, 536-537, 1961 
3. WITT, I., MULLER, H., KUNZER, W. Evidence for the existence of fetal fibrinogen. Thromb.Diathes.Haemorrh. 22, 101, 1969

4. WITT, I., KARITSKY, D., MULLER, H., KUNZER, W. Peptidmuster von hochgereinigtem Fibrinogen aus neugeborenen- und erwachsenen blut. Schweiz.Med.Wschr. 42, 98, 1684, 1968

5. WITT, I., MULLER, H. Phosphorus and Hexosecontent of human feta1 fibrinogen. Biochimica et Biophysica Acta. 221, 402-404, 1970

6. WITT, I., HASLER, K. Influence of organically bound phosphorus in fetal and adult fibrinogen on the kinetics of the interaction between thrombin and fibrinogen. Biochimica et Biophysica Acta. 271, 357-362, 1972

7. WITT, I., TESCH, R. Untersuchungen zur struktur des fetalen fibrinogens. Blut. $38,54,1979$.

8. TESCH, R., TROLP, R., WITT, I. Electronmicroscopic studies on the fetal fibrin clot. Thrombosis Research. 16, 239, 1979

9. WITT, I. Besonderheiten des blutgerinnungs und fibrinolyse systems bei neugeborenen. Fibrinolyse, Thrombose, Hämostase. Verhandlungen des I. Kongresses für thrombose und blutgerinnung. 212-217, 1980

Herausgeber: E. Deutsch, K. Lechner, F.K., Schattauer Verlag Stuttgart-New York.

10. GALANAKIS, D.K., MOSFSSON, M.W. Evaluation of the role of in vivo proteolysis (fibrinogenolysis) in prolonging the thrombin time of human umbilical cord fibrinogen. Blood, vol.48, no 1 (july 1976).

11. GALANAKIS, D.K., MOSESSON, M.W. Comparative studies on fetal fibrinogen from ful1-term and premature infants. Thrombosis and Haemostasis, 42:79 1979

12. GAJAANAKIS, D.K., MOSESSON, M.W. Correction of the delayed fibrin aggregation of fetal fibrinogen by partial removal of sialic acid. Thrombosis and Haemostasis, 42, 79, 1979

13. GUILliN, M.C., MENACHE, D. Fetal Fibrinogen-Fibrin Umwandlung im Nabelvenenblut. Med. Welt, 26/Heft 48, 1975

14. TEGER-NILSSON, A.C., EKELUND, H. Fibrinogen to fibrin transformation in umbillical cord blood and purified neonatal fibrinogen. Thrombosis Research, vol. $\underline{5}, 601-6121974$

15. KRAUSE, W.H., MAUS, W. Untersuchungen zur Fibrinogen-Fibrin Umwandlung im Nabelvenenblut. Med.Welt 26/Heft 48, 1975

16. LANE, D.A., ALLEN, A.K., MARKWICK, J., MACKIE, I., THOMPSON, E., OWEN, J. Carbohydrate composition and catapolism of five abnormal fibrinogens. Thrombosis and haemostasis, 46(1) 181, july 12, 1981. 